\title{
Article
}

\section{Dual wavelength (ultraviolet and green) photodetectors using solution processed Zinc Oxide nanoparticles}

Mohammed A. Ibrahem, Emanuele Verrelli, Khue T. Lai, Georgios

Kyriakou, Adam F. Lee, Mark A. Isaacs, Fei Cheng, and Mary O'Neill

ACS Appl. Mater. Interfaces, Just Accepted Manuscript • DOI: 10.1021/acsami.7b08092 • Publication Date (Web): 26 Sep 2017

Downloaded from http://pubs.acs.org on September 29, 2017

\section{Just Accepted}

"Just Accepted" manuscripts have been peer-reviewed and accepted for publication. They are posted online prior to technical editing, formatting for publication and author proofing. The American Chemical Society provides "Just Accepted" as a free service to the research community to expedite the dissemination of scientific material as soon as possible after acceptance. "Just Accepted" manuscripts appear in full in PDF format accompanied by an HTML abstract. "Just Accepted" manuscripts have been fully peer reviewed, but should not be considered the official version of record. They are accessible to all readers and citable by the Digital Object Identifier (DOI®). "Just Accepted" is an optional service offered to authors. Therefore, the "Just Accepted" Web site may not include all articles that will be published in the journal. After a manuscript is technically edited and formatted, it will be removed from the "Just Accepted" Web site and published as an ASAP article. Note that technical editing may introduce minor changes to the manuscript text and/or graphics which could affect content, and all legal disclaimers and ethical guidelines that apply to the journal pertain. ACS cannot be held responsible for errors or consequences arising from the use of information contained in these "Just Accepted" manuscripts. 


\title{
Dual Wavelength (Ultraviolet and Green)
}

\section{Photodetectors Using Solution Processed Zinc Oxide}

\section{Nanoparticles}

\author{
Mohammed A. Ibrahem ${ }^{1,2}$, Emanuele Verrelli ${ }^{1}$, Khue T. Lai $^{3}$, Georgios Kyriakou ${ }^{4}$, Adam F. Lee $^{4}$, \\ Mark A. Isaacs ${ }^{4}$, Fei Cheng ${ }^{1}$ and Mary O'Neill ${ }^{1,5^{*}}$
}

${ }^{1}$ School of Mathematics and Physical Sciences, University of Hull, Cottingham Rd., Kingston upon Hull HU6 7RX, United Kingdom.

${ }^{2}$ Laser Physics Branch, Department of Applied Sciences, University of Technology, Baghdad 10066, Iraq.

${ }^{3}$ School of Engineering and Computer Science, University of Hull, Cottingham Rd., Kingston upon Hull HU6 7RX, United Kingdom.

${ }^{4}$ European Bioenergy Research Institute, Aston University, Aston Triangle, Birmingham B4 7ET, United Kingdom.

${ }^{5}$ School of Science and Technology, Nottingham Trent University, Clifton Lane, Nottingham NG11 8NS, United Kingdom.

\section{*Corresponding email: mary.oneill@ntu.ac.uk}

KEYWORDS: persistent photoconductivity; $\mathrm{ZnO}$ nanoparticles; photolithography; imaging photodetectors; defects. 


\begin{abstract}
Narrow-band photoconductivity with a spectral width of $0.16 \mathrm{eV}$ is obtained from solutionprocessed colloidal $\mathrm{ZnO}$ nanocrystals beneath the band-edge at $2.25 \mathrm{eV}$. A new model involving electron transfer from deep defects to discrete shallow donors is introduced to explain the narrow spectrum and the exponential form of the current rise and decay transients. The defects are tentatively assigned to neutral oxygen vacancies. The photocurrent responsivity can be enhanced by storage in air and this correlates with the formation of carbonate surface species by capture of carbon dioxide during storage. This controllability is exploited to develop a low-cost and scalable photolithographic approach to pixelate photodetectors for applications such as object discrimination, sensing etc. The spectral response can be spatially patterned so that dual (ultraviolet and green) and single (ultraviolet only) wavelength detecting $\mathrm{ZnO}$ pixels can be produced on the same substrate. This presents a new sensor mode with applications in security or full colour imaging.
\end{abstract}

\title{
1. Introduction
}

Solution processable $\mathrm{ZnO}$ is a promising electronic and optoelectronic material because of its compatibility with low-cost and highly scalable manufacturing for the next generation of smart products for the internet of things, wearable technologies, mobile medical devices, security etc. These applications require device technologies such as transistors, light-emitting diodes, photodetectors, sensors etc. Solution processed $\mathrm{ZnO}$ is well studied as the semiconducting material for thin-film transistors. ${ }^{1}$ From the optoelectronic perspective, it is often combined with organic materials to improve electron injection or collection in hybrid organic light-emitting diodes, photovoltaics and photodiodes. ${ }^{2,3,4,5}$ There is also an extensive literature on ultraviolet 
photoconductivity (PC) from solution processed $\mathrm{ZnO} .{ }^{6,7,8,9}$ For example, core-shell nanorods of $\mathrm{ZnO} / \mathrm{CdS}$ were used to make a self-powered dual wavelength photodetector $\mathrm{ZnO} \mathrm{CdS}$ operating in both the ultraviolet and blue-green spectral regions. ${ }^{10}$ Such multispectral photodetectors are interesting for applications such as discrimination of objects, lab on a chip, environmental and biological sensing, Low-cost, electronic and optoelectronic materials must be easily patterned in order to achieve the promise of the disruptive technologies mentioned above, but there is limited work to date on the patterning of $\mathrm{ZnO}$. Thin $\mathrm{ZnO}$ seed layers are often used to seed the growth of vertical $\mathrm{ZnO}$ nanowires by solution processing or chemical vapour deposition and the growth can be patterned by masking the seed layers with patterned photoresist. ${ }^{11}$ Alternatively the seed layers can be patterned photolithographically or by inkjet printing. ${ }^{12}$ Zinc oxide vertical nanowire arrays have also been sculpted to form 3-dimensional patterns using photolithography. 13 A photolithographic approach was used to pattern $\mathrm{ZnO}$, deposited by spray pyrolysis, to modify the electron injection barrier of a gold/organic semiconductor interface and so improve the efficiency of a light-emitting, organic field-effect transistor. ${ }^{14}$

The conductivity, $\sigma$, of a semiconductor is given as $\sigma=\left(n e \mu_{e}+p e \mu_{h}\right)$ where $n$ and $p$ are the density of electrons and holes respectively and $\mu_{\mathrm{n}}$ and $\mu_{\mathrm{p}}$ their respective mobility. PC results in a change of conductivity by irradiation with light normally as a result of the increase in $n$ and/or p. No energy is generated and the current is provided by the external circuit via the contacts, reducing to zero as the applied field goes to zero. $\mathrm{ZnO}$ shows $\mathrm{PC}$ with response times in the nanoseconds regime determined by electron-hole recombination, ${ }^{15,16}$ but there are also many examples of persistent PC. ${ }^{6,16,17} \mathrm{ZnO}$ is an $\mathrm{n}$ type semiconductor with a very deep valence band so it is generally assumed that the persistent photocurrent is carried by excess electrons. The 
generally agreed mechanism is that a low conductivity depletion region is generated at the surface of $\mathrm{ZnO}$ in the dark because electrons are trapped by the adsorption of gaseous oxygen according to the reaction $\mathrm{O}_{2(\mathrm{~g})}+e^{-} \rightarrow \mathrm{O}_{2}^{-}$. Free electrons and holes are photogenerated by absorption of light with above band-gap energy. The holes migrate to the $\mathrm{ZnO}$ surface along the potential gradient produced by band bending where they release the adsorbed oxygen according to the reaction $\mathrm{O}_{2}^{-}+h^{+} \rightarrow \mathrm{O}_{2(\mathrm{~g})}$. The persistent photocurrent build-ups over the timescale of the electron lifetime, which may be seconds or longer. This is determined by trapping or scavenging via surface electrochemical reactions etc. A photoconductive gain (equal to the number of electrons generated per photon) greater than one is often observed as the electrons pass multiple times across the circuit. ${ }^{18}$ The PC signal may also have a contribution from the reduction of the injection barrier at the Schottky contacts due to the trapping of photogenerated holes in the depletion layers. ${ }^{16,18}$ There are reports of nominally undoped $\mathrm{ZnO}$ showing PC below band-edge and in the visible spectral range. The visible PC is spectrally broad and is attributed to transitions between various defect states and the conduction or valence band. ${ }^{17,19}$

In this paper we discuss narrow-band persistent $\mathrm{PC}$ below the band-edge of colloidal $\mathrm{ZnO}$ nanocrystals. The transitions observed in the green spectral region are sharp, which means that charge transfer occurs between discrete states rather than to the broad conduction or valence band. This is different to most sub-band gap PC, which occurs over a broad spectral range, resulting from optical transitions between defect states and the conduction or valence band. We propose a model based on defect and shallow donor states to explain the spectral and temporal dependence of the photocurrent. We show how device processing and storage can be controlled to increase the density of defects and so enhance PC in the green. The photoconductive thin films 
are solution processable and we demonstrate that they can be patterned using photolithography to obtain a dual wavelength photodetector. A multi-step photolithography allows different pixels to have different spectral responses; one is sensitive to both green and ultraviolet light whilst the green response is suppressed in another.

\section{Experimental Section}

\subsection{Preparation of the $\mathrm{ZnO} N \mathrm{NS}$ :}

A $\mathrm{ZnO}$ nanoparticle (NP) solution was prepared using literature methods with some modification. ${ }^{20,21}$ Zinc acetate $\left(\mathrm{Zn}(\mathrm{OAc})_{2}, 0.8182 \mathrm{~g}, 4.46 \mathrm{mmol}\right)$ and $0.25 \mathrm{ml}$ of water were added into a three-neck flask containing $42 \mathrm{ml}$ of methanol. The solution was heated to $60{ }^{\circ} \mathrm{C}$ and then a solution of potassium hydroxide $(0.4859 \mathrm{~g}, 7.22 \mathrm{mmol})$ in methanol $(23 \mathrm{ml})$ was dropped slowly into the flask. The reaction took place at $60{ }^{\circ} \mathrm{C}$ for 2 hours. White ZnO NPs were obtained after centrifuging and washing with methanol twice. These were dried in air for $30 \mathrm{~min}$ and then dissolved in a solution of chloroform $(6.2 \mathrm{~mL})$ containing a small amount of octylamine (0.2 mL). Finally, a clear $\mathrm{ZnO}$ nanoparticle solution was obtained after filtering through a 0.45 $\mu \mathrm{m}$ PTFE filter.

\subsection{Device fabrication and characterization:}

A $\mathrm{ZnO} \mathrm{NP}$ solution of concentration $2.5 \%$ by weight in chloroform was spin cast through a $0.45 \mu \mathrm{m}$ polytetrafluoroethylene (PTFE) syringe filter onto a patterned glass substrate at 2000 $\mathrm{rpm}^{-1}$ for $30 \mathrm{sec}$. The substrate, purchased from Ossila, was pre-patterned with indium tin oxide 
fingers $(20 \Omega$ /square) of overall channel dimensions of $30 \mathrm{~mm} \times 50 \mu \mathrm{m}$. The resulting $\mathrm{ZnO}$ layer thickness was around $120 \mathrm{~nm}$ and the sample was baked at $100{ }^{\circ} \mathrm{C}$ for $10 \mathrm{~min}$. Samples were then annealed on a hot plate using various temperatures and annealing atmospheres as discussed in the text. The photocurrent characteristics of the photodetector device were tested on excitation with a $150 \mathrm{~W}$ Xenon light source equipped with a $5 \mathrm{~nm}$ bandwidth monochromator and a set of lenses to give a rectangular shaped light beam covering the active device. The beam intensity was typically $0.31 \mathrm{~mW} \mathrm{~cm}^{-2}$ and $0.5 \mathrm{~mW} \mathrm{~cm}^{-2}$ at $360 \mathrm{~nm}$ and $550 \mathrm{~nm}$ respectively. Photocurrent transients were also measured in a nitrogen filled glove box using a laser diode with wavelength of $532 \mathrm{~nm}$ and power $0.15 \mathrm{~mW}$. The optical system was interfaced to the Keithley 2400 source meter using BenWin ${ }^{+}$software to measure the photocurrent density as a function of wavelength and time. Optical absorption spectra were measured using Thermo Scientific (EVOLUTION 220) spectrophotometer over the wavelength range from $300 \mathrm{~nm}$ to $700 \mathrm{~nm}$. High resolution TEM was recorded using a Cs aberration-corrected JEOL $2100 \mathrm{~F}$ microscope at $200 \mathrm{kV}$. X-ray photoelectron spectroscopy (XPS) measurements were performed on a Kratos AXIS HSi spectrometer equipped with a charge neutralizer and monochromated Al K $\alpha$ excitation source $(1486.7 \mathrm{eV})$, with energies referenced to adventitious carbon at $284.6 \mathrm{eV}$. Spectral fitting was performed using CasaXPS version 2.3.15. Samples were not sputtered prior to analysis to avoid perturbing the surface composition, and stored and handled in air.

A Bruker IFS 66/S Fourier transform infrared (FTIR) spectrometer equipped with a watercooled glowbar source, potassium bromide beam splitter and deuterated triglycine sulphate detector was used to measure the transmittance, $I / I_{o}$, of the samples at room temperature. $I$ is the intensity of the transmitted light through the sample and semi-insulating gallium arsenide (GaAs) substrate and $I_{o}$ is the intensity of the transmitted light through the GaAs substrate only. The 
GaAs substrate spectrum was taken under the same conditions as each sample measurement in order to eliminate any inherent artifacts. The resolution was $4 \mathrm{~cm}^{-1}$ and 1000 scans were recorded, co-added and then averaged for each spectrum. The sample compartment was continuously purged with dry air to reduce absorptions from atmospheric water vapor and carbon dioxide.

\section{Results and Discussions}

\subsection{Physical characterization}

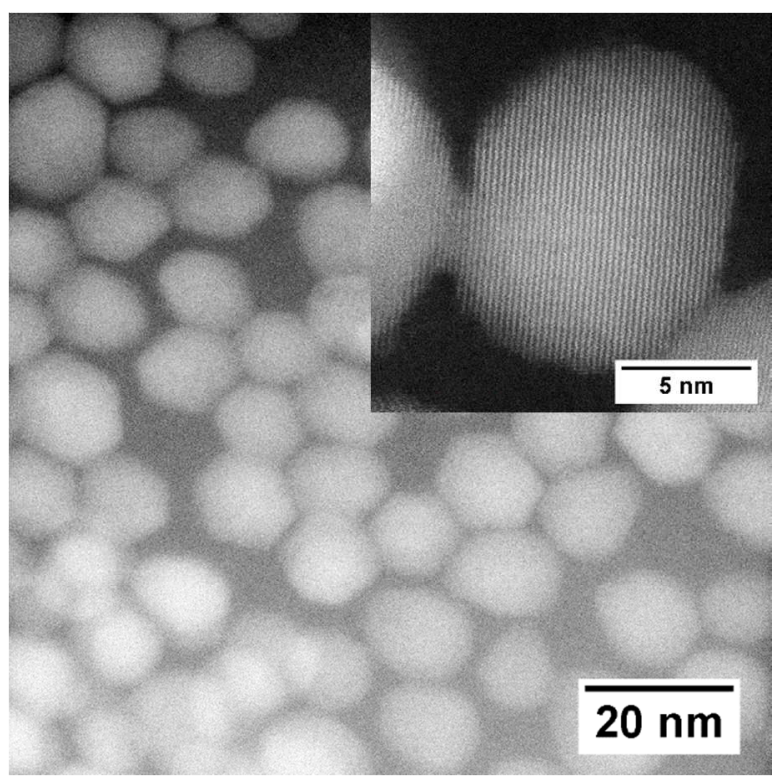

Figure 1. TEM dark field image of the as synthesized ZnO NPs. The inset shows a dark field high-resolution TEM image of a crystalline ZnO NP.

Transmission electron microscopy (TEM) results (Figure 1) show that the ZnO NPs are crystalline with an average diameter of $11.8 \pm 1.7 \mathrm{~nm}$ (based upon analysis of $>100$ particles) and a d-spacing of $0.26 \mathrm{~nm}$ for the $\left(\begin{array}{lll}0 & 0 & 2\end{array}\right)$ lattice plane, see Figure 1 inset. Figure $\mathrm{S} 1$ of the 
supporting information shows an X-ray diffraction scan, confirming the wurtzite phase of the $\mathrm{ZnO}$ NPs. Figure 2(a-c) show the $\mathrm{O} 1 \mathrm{~s}$ and $\mathrm{C} 1 \mathrm{~s}$ and $\mathrm{Zn} 2 \mathrm{p}$ XPS spectra of ZnO NPs. The samples were spin coated on $\mathrm{Si}$ substrates, and then annealed at $350{ }^{\circ} \mathrm{C}$ in $\mathrm{N}_{2}$ or air. The $\mathrm{Zn}: \mathrm{O}$ atomic ratio was essentially the same for annealing under both environments at $\sim 0.65$, somewhat lower than expected for stoichiometric $\mathrm{ZnO}$ indicating the presence of oxygen vacancies. In contrast, the $\mathrm{C}: \mathrm{O}$ atomic ratio was higher for the sample prepared and annealed in $\mathrm{N}_{2}$ compared to air ( 0.86 versus 0.65 respectively). The $\mathrm{N}_{2}$ annealed sample also contained trace surface nitrogen, together suggesting incomplete decomposition of the octylamine stabilizer during nitrogen thermal processing. Zn 2p XPS spectrum (Figure 2(a)) exhibited a single chemical environment at $1021.4 \mathrm{eV}$ binding energy consistent with $\mathrm{Zn}^{2+}$ in $\mathrm{ZnO}{ }^{22,23}$ The $\mathrm{O}$ 1s spectra (Figure 2(b)) exhibited three distinct chemical environments which were fitted according to Zhang et al to: ${ }^{24}$ lattice oxygen lattice $\left(\mathrm{O}_{\mathrm{L}}\right)$ in $\mathrm{ZnO}$ at $530.14 \mathrm{eV}$, oxygen vacancies $\left(\mathrm{O}_{\mathrm{V}}\right)$ at $531.24 \mathrm{eV}$, and either a dissociated oxygen species $\left(\mathrm{O}_{\mathrm{C}}\right)$ or surface hydroxyls (which possess a higher intensity following annealing in air) at $532.2 \mathrm{eV} .{ }^{25}$ The ratio of $\left(\mathrm{O}_{\mathrm{L}}\right)$ : $\left(\mathrm{O}_{\mathrm{V}}\right)$ : $\left(\mathrm{O}_{\mathrm{C}}\right)$ components for the air annealed sample was $1.0: 0.24: 0.14$ while that for the $\mathrm{N}_{2}$ annealed sample was extremely similar at $1.0: 0.27: 0.21$, indicating a similar surface concentration of oxygen vacancies following both pretreatments. The C1s XPS spectra (Figure 2(c)) of both samples exhibit two distinct chemical environments, a strong feature at $284.4 \mathrm{eV}$ consistent with an aliphatic hydrocarbon chain arising from the octylamine stabilizer, and a weak high binding feature at $288.9 \mathrm{eV}$ indicative of a carboxylate ${ }^{26}$ arising from either partial decomposition of the acetate precursor, or adsorption of atmospheric $\mathrm{CO}_{2}$ during sample storage and handling in air. Since the $\mathrm{ZnO}$ NPs were annealed to $350{ }^{\circ} \mathrm{C}$ prior to XPS analysis, sufficient to fully decompose the zinc acetate precursor, ${ }^{27}$ the former possibility can be discounted, with carbonate formation 
simply reflecting atmospheric $\mathrm{CO}_{2}$ adsorption. Figure 3(a) shows the FTIR spectrum of a thin film of $\mathrm{ZnO}$ without annealing. The $\mathrm{ZnO}$ backbone transitions are observed about $500 \mathrm{~cm}^{-1}$. There are a number of transitions relating to the acetate ligand groups (from the starting precursor) chelated with zinc atoms on the surface of nanocrystals and the added octylamine ligands. ${ }^{7,28,20,29}$ A thick sample was used, so some of these transitions are saturated. Annealing in air at $350{ }^{\circ} \mathrm{C}$, see Figure 3(b1), removes significantly the octylamine and the acrylate groups in agreement with the XPS data. This is shown by the large reduction in the stretch C-O transitions between 1000 and $1150 \mathrm{~cm}^{-1}$, the $\mathrm{C}-\mathrm{H}$ bends between $620 \mathrm{~cm}^{-1}$ and $950 \mathrm{~cm}^{-1}$ and the sharp stretching C-H transitions between 2850 and $2950 \mathrm{~cm}^{-1}$. Note the saturated unidentate transitions, $\mathrm{C}=\mathrm{O}$ at about $1570 \mathrm{~cm}^{-1}$ and $\mathrm{C}-\mathrm{O}$ doublet at $1415 \mathrm{~cm}^{-1}$ and $1450 \mathrm{~cm}^{-1}$, from the precursor acetate groups are nearly completely removed on annealing in air, as shown in Figure 3(b1) and 3(c1). However transitions at similar wavelengths, i.e. at $1565 \mathrm{~cm}^{-1}, 1419 \mathrm{~cm}^{-1}$ and $1454 \mathrm{~cm}^{-1}$, increase significantly after storage of the thin films in air for 15 days, see Figure 3(b2). Only a very small increase in these transitions is observed when the sample is stored in a nitrogen environment with $\mathrm{O}_{2}, \mathrm{H}_{2} \mathrm{O}<1.5-2$ PPM, see Figure 3(c2), for the same time. This is consistent with $\mathrm{CO}_{2}$ adsorption by $\mathrm{ZnO}$ from the atmosphere to form surface carbonate. A comparison of Figure 3(c) and 3(d) shows that an oxidizing air rather than a nitrogen annealing environment assists the removal of the precursor acetate ligands from the $\mathrm{ZnO}$ thin film. The FTIR spectrum of the nitrogen annealed sample does not change significantly following storage in nitrogen for 15 days. The broad absorbance band around $3500 \mathrm{~cm}^{-1}$, originating from adsorbed $\mathrm{OH}$ groups, is present in air and nitrogen samples, and is of higher intensity for the former as expected due to greater surface hydroxylation consistent with the O 1s XPS spectra. The interaction of $\mathrm{ZnO}$ nanoparticle with atmospheric $\mathrm{CO}_{2}$ can lead to a variety of adsorbed species depending on the 
presence or absence of humidity in the gas atmosphere. Possible adsorbed species include monodentate and bidentate carbonate species formed by the direct interaction of gaseous carbon dioxide $\left(\mathrm{CO}_{2(\mathrm{~g})}\right)$ with surface oxide anions and oxygen vacancies (v) in the absence of water (Equations 1 and 2) and bicarbonate from the interaction of $\mathrm{CO}_{2(\mathrm{~g})}$ with surface hydroxyl groups present under humid environments (Equation 3). ${ }^{30}$ The strong IR absorption bands at $\sim 1565 \mathrm{~cm}^{-1}$, in addition to those at 1419 and $1454 \mathrm{~cm}^{-1}$ suggest that both bidentate and monodentate adsorbed carbonate are formed.
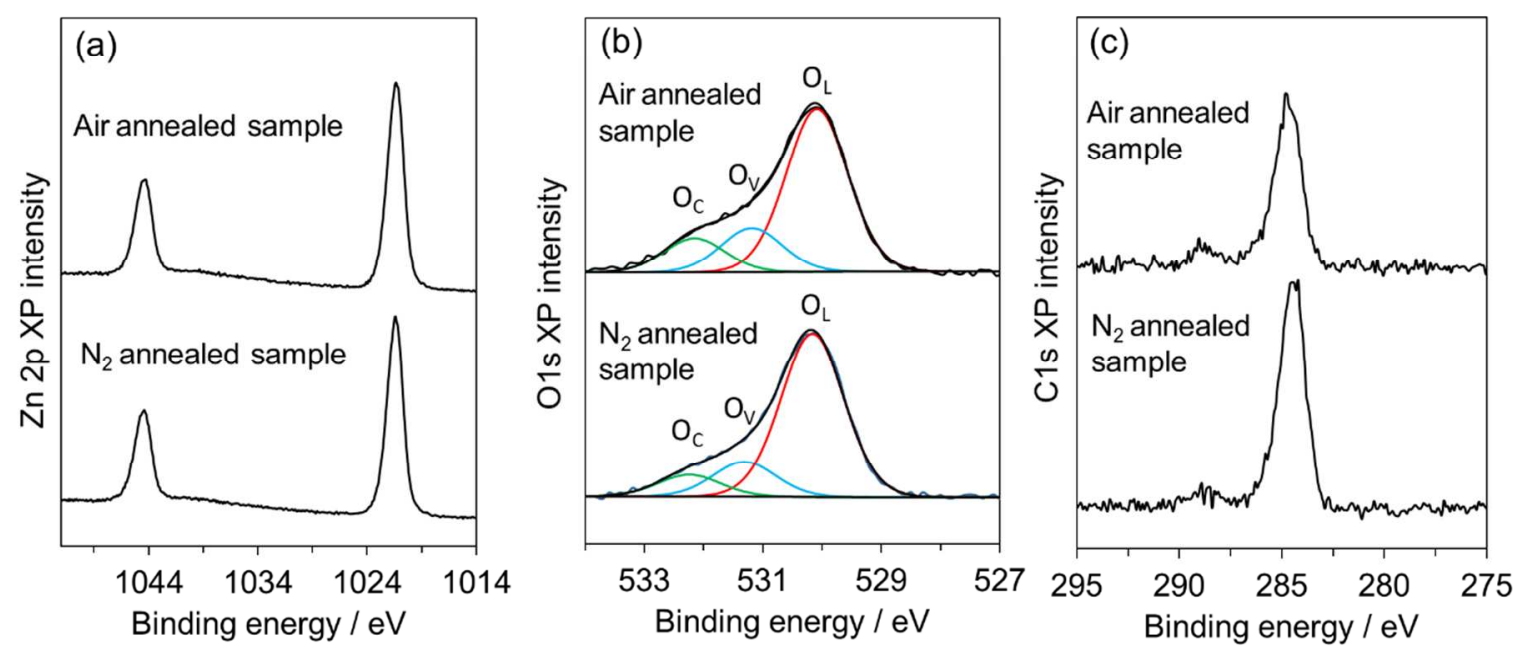

Figure 2. High resolution (a) Zn 2p (b) O 1s and (c) C 1s XPS spectra of ZnO NPs, which were spin-coated prior to annealing either in $\mathrm{N}_{2}$ or air at $350{ }^{\circ} \mathrm{C}$.

$$
\begin{aligned}
& \mathrm{Zn}-\mathrm{O}+\mathrm{CO}_{2}(\mathrm{~g}) \mathrm{ZnCO} \mathrm{O}_{3} \text { (monodentate) } \\
& \mathrm{Zn}-\mathrm{v}-\mathrm{Zn}-\mathrm{O}+\mathrm{CO}_{2}(\mathrm{~g}) \rightleftarrows \mathrm{ZnCO}_{3} \text { (bidentate bridging) } \\
& \mathrm{Zn}-\mathrm{OH}+\mathrm{CO}_{2}(\mathrm{~g}) \rightleftarrows \mathrm{ZnHCO}_{3} \text { (bicarbonate) }
\end{aligned}
$$




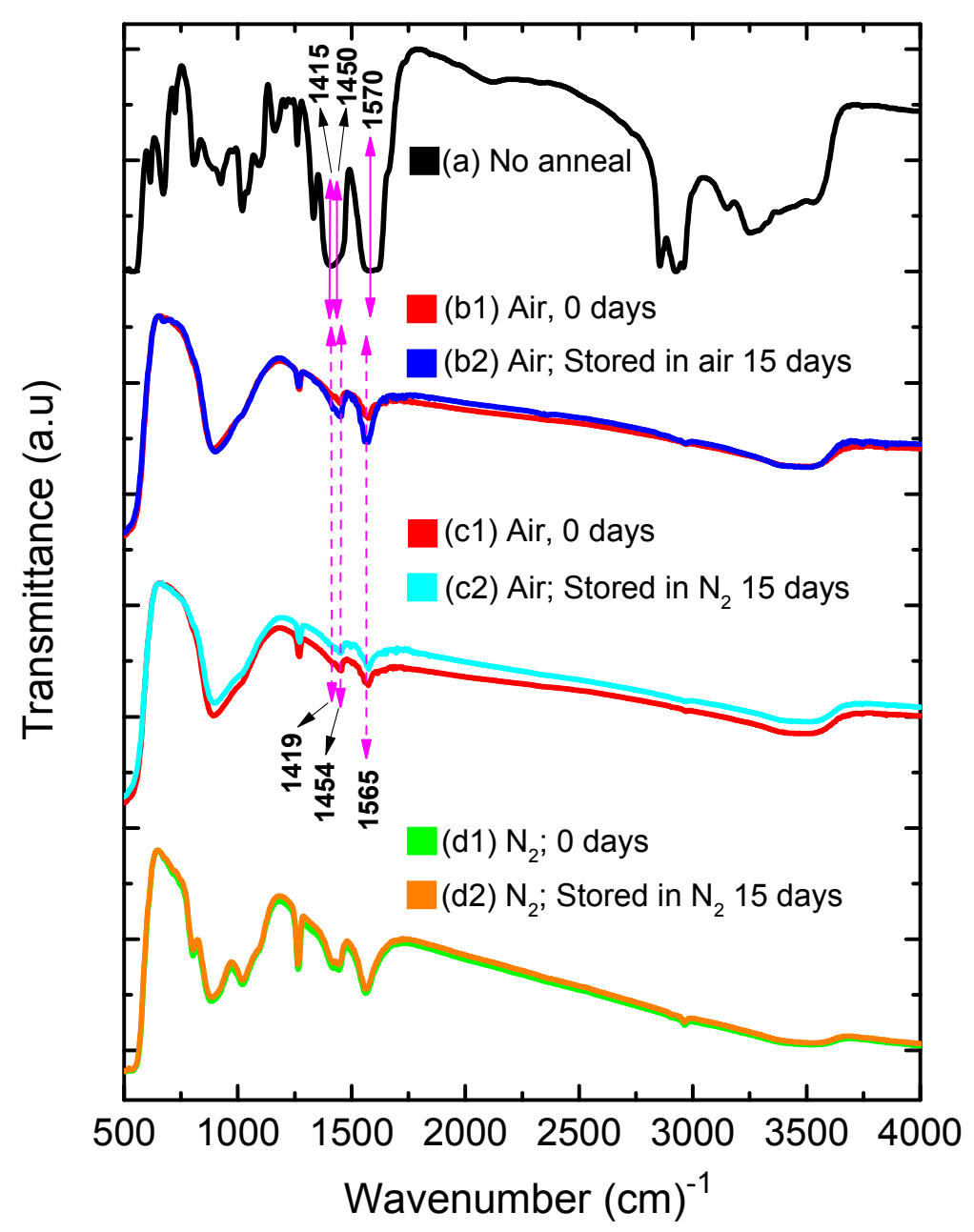

Figure 3. FTIR spectrum of thin films of $\mathrm{ZnO}$ drop-cast onto a semi-insulating GaAs substrate using different preparation and storage conditions: (a) Sample was baked at $100{ }^{\circ} \mathrm{C}$ to remove solvent; (b1) Sample annealed at $350{ }^{\circ} \mathrm{C}$ in air for 1 hour, measured immediately and (b2) after storage in air for 15 days; (c1) Sample annealed at $350{ }^{\circ} \mathrm{C}$ in air for 1 hour, measured immediately and then (c2) after storage in nitrogen for 15 days; (d1) Sample annealed at $350{ }^{\circ} \mathrm{C}$ in nitrogen for 1 hour, measured immediately and (d2) after storage in nitrogen for 15 days. The spectra are shifted vertically for clarity. The vertical lines and labelled transitions clarify the differences in wavenumber between the $\mathrm{C}-\mathrm{O}$ transition in the unannealed sample and following annealing and storage in air. 


\subsection{Photoconductivity}

(a)

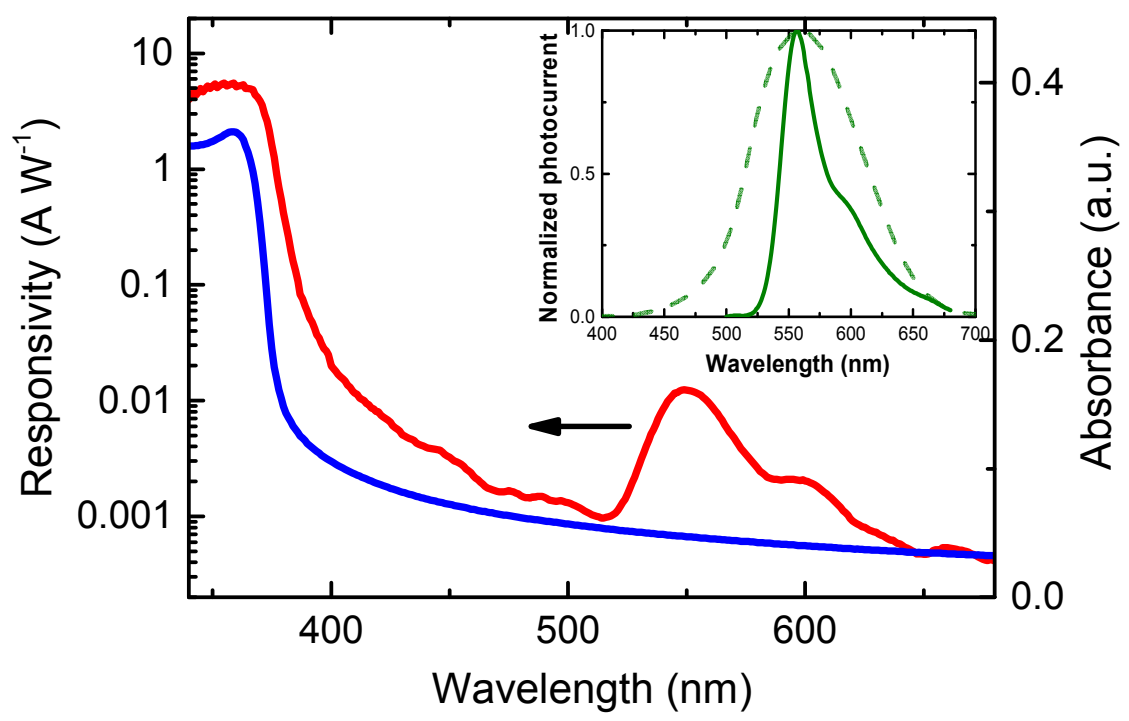

(b)

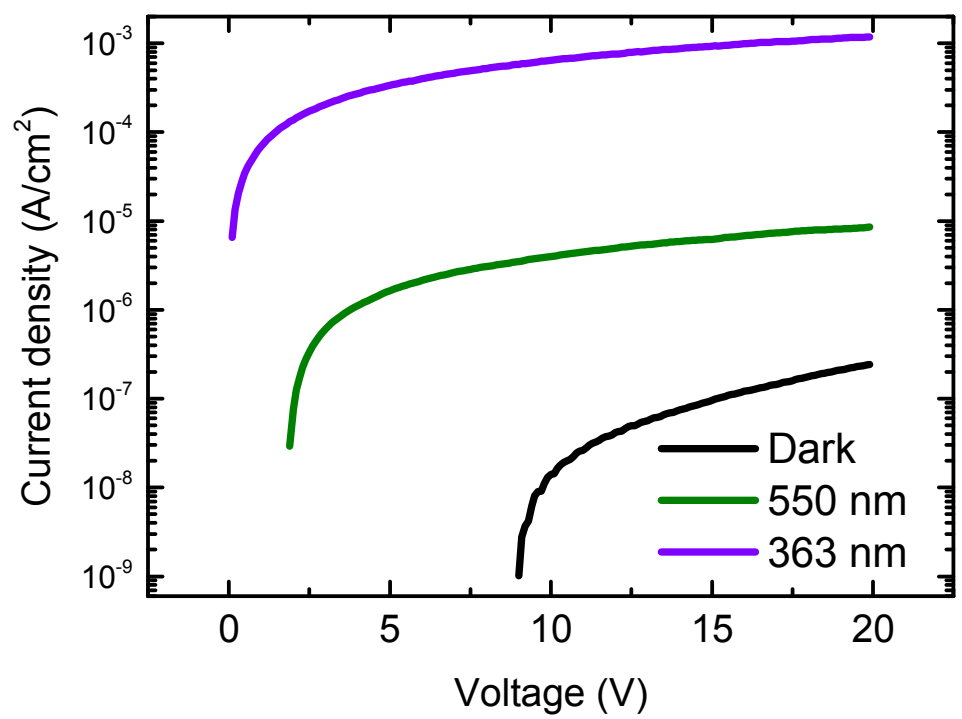

Figure 4. (a) Semi-log plot of absorbance and photocurrent responsivity spectra from a thin film of $\mathrm{ZnO}$ NPs following annealing at $350{ }^{\circ} \mathrm{C}$ in air for 2 hours. The inset shows that the visible photocurrent spectrum (solid line), measured on application of a voltage $20 \mathrm{~V}$ across a planar device length of $5 \mu \mathrm{m}$, and the green colour matching function (dashed line) of the CIE colour 
system. (b) Current density versus applied field in the dark and on application of light of intensity of $0.31 \mathrm{~mW} \mathrm{~cm}$ and $0.5 \mathrm{~mW} \mathrm{~cm}^{-2}$ at a wavelength of $363 \mathrm{~nm}$ and $550 \mathrm{~nm}$ respectively.

Figure 4(a) shows semi-log plots of the optical absorption and photocurrent spectra of $\mathrm{ZnO}$ film. The strong excitonic absorption peak around $360 \mathrm{~nm}$ shows a small quantum confinement effect compared with the peak of bulk $\mathrm{ZnO}$ at about $370 \mathrm{~nm}$. A weak absorption tails decays into the visible region of the spectrum, which is attributed to below band-edge defect states. The responsivity of the photocurrent peaks at $5.3 \mathrm{~A} \mathrm{~W}^{-1}$ in the $\mathrm{UV}$. The expected tail in the visible is accompanied by a remarkable narrow-band photocurrent with a peak responsivity of $10.2 \mathrm{~mA}$ $\mathrm{W}^{-1}$ at $550 \mathrm{~nm}$ and a shoulder at $596 \mathrm{~nm}$. Noting that the responsivity of $\mathrm{ZnO}$ photodetector depends on defect concentration, the UV responsivity reported here is comparable to that reported by others, e.g. $61 \mathrm{~A} \mathrm{~W}^{-1}$ for colloidal NPs by Greenham et al ${ }^{18}$ and $1.1 \mathrm{~A} \mathrm{~W}^{-1}$ for a sol-gel $\mathrm{ZnO}$ film by Chen et al. ${ }^{31}$ The reduced responsivity in the visible spectrum is compatible with the literature. For example, $\mathrm{ZnO}$ nanowires show a UV responsivity of $2 \times 10^{-2} \mathrm{~A} \mathrm{~W}^{-1}$, whilst the corresponding broad-band responsivity in the visible is $10^{-5} \mathrm{~A} \mathrm{~W}^{-1} \cdot{ }^{32}$ The inset of Figure 4(a) shows the visible PC spectrum on a linear scale. Its full width at half maximum (FWHM) is about $40 \mathrm{~nm}$ with some sample dependent variation in the relative heights of the peak and shoulder. There is no corresponding visible feature in the absorption spectrum, indicating that a low density of the defect states is associated with the PC, which must have a much higher photoactivity than the defects associated with broadband visible absorption. As the inset shows, the green PC spectrum is completely contained within the green colour matching function of the CIE colour system, showing its applicability for green imaging devices. Figure 4(b) shows the UV and green photocurrent as well as the dark current as a function of voltage. The photocurrent is linear with voltage in both cases. We note also the dark current and green 
photocurrent curves are offset from zero, indicating a low level of charge separation or charge trapping. The time dependence of the photocurrent in the UV and green is shown using a semi$\log$ plot in Figure S2. The UV signal has a rise time of less than $0.5 \mathrm{~s}$ and this increases as the intensity of the irradiation decreases.

\subsection{Origin of green photoconductivity}

There is a fundamental difference between the visible PC reported here and reports in the previous literature, ${ }^{17,33,34,35,36,19}$ which show PC over a broad spectral range, with typical spectral width $>100 \mathrm{~nm}$. These are attributed to optical transitions between defect states and the conduction or valence band. For example, Kavitha et al. ${ }^{37}$, and others ${ }^{38,39}$ studied the $\mathrm{ZnO}$ photoconductivity in the visible and assigned it to the electron transitions between sub-band gap ionized energy levels introduced by the oxygen vacancies and the conduction band. The visible photocurrent spectrum shown in the inset of Figure 4(a) cannot involve transitions to a continuous band because the two transitions, peak at $550 \mathrm{~nm}$ and shoulder at $596 \mathrm{~nm}$, are spectrally narrow. Therefore discrete states must be involved. In suggesting a model to explain the origin of $\mathrm{PC}$, we are hampered by the huge variation in attribution of defect states to spectral transitions in the literature. Therefore our proposed model can only be tentative. For example, the green luminescence in $\mathrm{ZnO}$ has been linked to transitions involving $\mathrm{Zn}$ vacancies, ${ }^{40}$ oxygen vacancies, ${ }^{19,41}$ etc. Jannotti and Van de Walle calculate the transition energies of various defects. These are the Fermi energies at which the formation energies of two charge states are the same. ${ }^{40}$ They, and others, ${ }^{42}$ show that, the $\mathrm{Zn}$ vacancy is a deep acceptor with a low formation energy. It exists in its double ionised state, $V_{\mathrm{Zn}}^{2-}$ in $n$ doped $\mathrm{ZnO}$, since the transition from the to 2- charge state occurs at a Fermi energy of $0.87 \mathrm{eV}$ above the valence band maximum. It is 
often passivated by hydrogen substitution, since strong $\mathrm{O}-\mathrm{H}$ bonds are formed. Oxygen vacancies have deep donor states in $\mathrm{ZnO}$ and can exist in one of three different charge states. The neutral state, $V_{O}^{0}$ contains two electrons, which may be removed to form $V_{O}^{+}$and $V_{O}^{2+}$ respectively. In $n$ type conditions, the Fermi level is near the conduction band, so that the neutral state is stable with a calculated energy about $2.0 \mathrm{eV}$ below the conduction band minimum. The concentration of defects has an inverse exponential dependence on their formation energy. ${ }^{40}$ The calculations predict that oxygen vacancies have a high formation energy and so exist at low concentrations. However, the surface density of oxygen vacancies in ZnO NPs should be much higher than in bulk because of their large surface area.

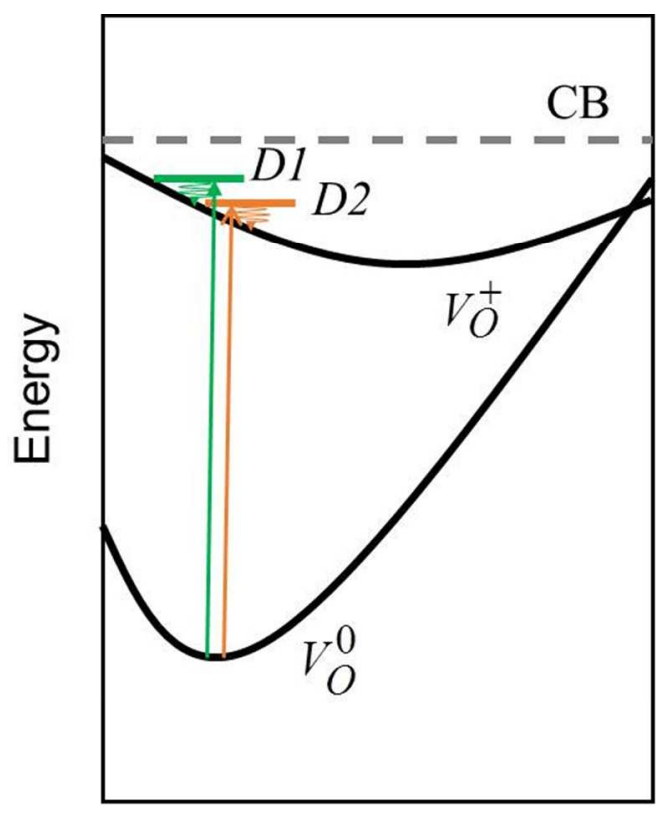

Config. Coordinate

Figure 5. Illustration of proposed model to describe discrete PC transitions. The minimum energy of the oxygen vacancy defect occurs at different values of the lattice configurational 
coordinate for the $V_{O}^{0}$ and $V_{O}^{+}$states. The electron is transferred from the $V_{O}^{0}$ state to a nearby ionised donor according to equation 4 . Two discrete donors, $D 1$ and $D 2$, account for the PC peak at 550 and shoulder at $596 \mathrm{~nm}$ respectively. The ionized $V_{O}^{+}$state then relaxes by lattice deformation to its equilibrium position.

We now discuss a model to explain PC at the two discrete wavelengths of $550 \mathrm{~nm}$ and $596 \mathrm{~nm}$ below the band-gap of $\mathrm{ZnO}$. We assume that electron transfer comes from the $V_{O}^{0}$ defect, because of the good match of its energy to theory and the non-stoichiometric $\mathrm{Zn}$ and $\mathrm{O}$ ratio of the NPs, as shown by XPS. However a similar model would be relevant for the $V_{Z n}^{2-}$ defect. The model is illustrated in Figure 5. PC arises by electron exchange between the vacancy and two local and independent donors as follows:

$$
V_{O}^{0}+D 1^{+}+h v_{550}=V_{O}^{+}+D 1^{0} \text { and }
$$$$
V_{O}^{0}+D 2^{+}+h v_{596}=V_{O}^{+}+D 2^{0}
$$

The subscript in the photon energy term refers to the peak wavelength of each of the two transitions. The photon energy matches the energy difference between that of the neutral vacancy and the ionized shallow donor $D^{+}$, which gains an electron. First principle calculations show thathe $V_{O}^{+}$state is thermodynamically unstable. ${ }^{40,43,39}$ However, as illustrated in the configuration coordinate diagram of Figure 5, it is stabilized by lattice interaction (i.e. 
displacement of nearest neighbor $\mathrm{Zn}$ atoms from their equilibrium positions) into a metastable state, the minimum energy of which occurs at a completely different lattice coordinate to that of the $V_{O}^{0}$ state. This means that there is a significant activation barrier for decay of the metastable $V_{O}^{+}$state to reform the $V_{O}^{0}$ state. Interestingly, electron paramagnetic resonance and Hall experiments with $\mathrm{ZnO}$ show the presence of two distinct shallow donors, one of which is associated with hydrogen. ${ }^{44}$

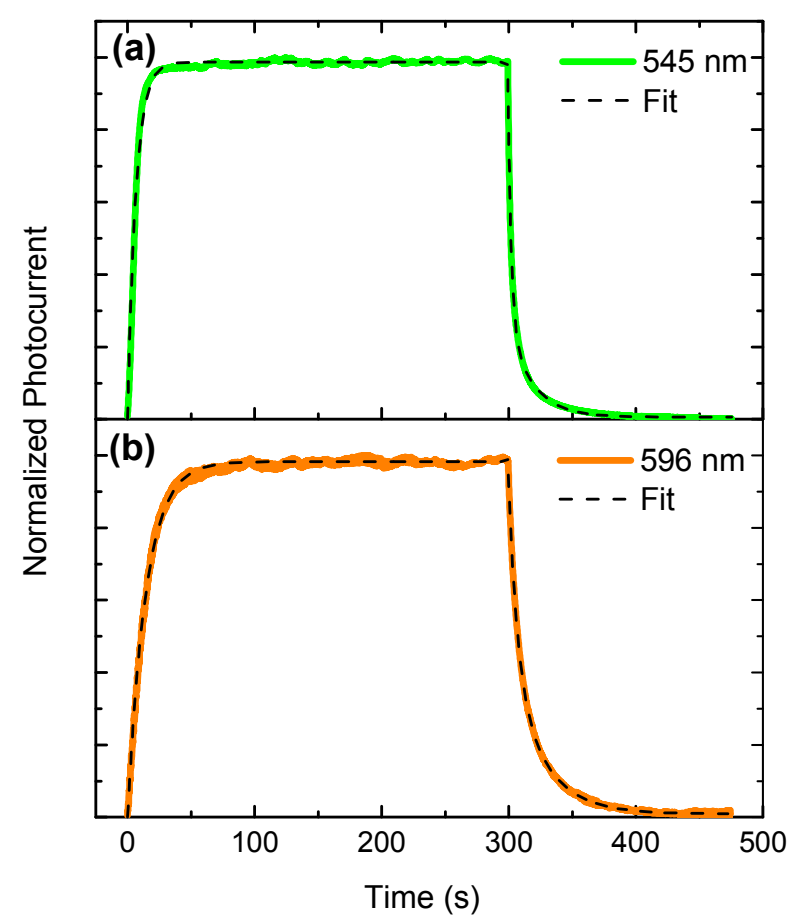

Figure 6. Normalised photocurrent as a function of time in response to incident light pulse at (a) $545 \mathrm{~nm}$ and (b) $596 \mathrm{~nm}$ and length 300s. Both wavelengths have the same intensity of $0.52 \pm$ $0.03 \mathrm{~mW} \mathrm{~cm}^{-2}$. The rising photocurrent part of the transients is fitted to the monoexponential function given in equation 5. The decay part of both curves is fitted to a biexponential function given in equation 6 . 
Let us now consider the temporal response to support the existence of two independent donors, D1 and D2. As discussed above, it is generally assumed that photocurrent in $\mathrm{ZnO}$ is carried by excess electrons. Persistent photocurrent transients in $\mathrm{ZnO}$ have long time constants, which can vary from seconds to hours, depending on the lifetime of the excess electrons. ${ }^{33,36,45,46}$ Electrons can decay by recombination, trapping or by electrochemical reactions with surface groups or atmospheric species. The transients are mostly non-exponential because different traps have different trapping times and saturation effects. Figure 6 shows the normalized temporal response of the photocurrent at (a) $545 \mathrm{~nm}$ and (b) $596 \mathrm{~nm}$ in response to an optical pulse of length $300 \mathrm{~s}$. The rising transient of the current is well described by a single exponential, as shown by the fitted lines in Figure 6 using the following equation:

$$
J(t)=J_{0}+A_{1}\left[1-\exp \left(-\frac{t}{\tau_{1}}\right)\right]
$$

The time constant $\tau_{1}$ is $6.5 \mathrm{~s}$ and $14.5 \mathrm{~s}$ for the transitions at $545 \mathrm{~nm}$ and $596 \mathrm{~nm}$ respectively. The mono-exponential fits, with a different time constant for each transition, indicates that electron transfer occurs by a single but different route in each case.

$$
J(t)=J_{0}+A_{1} \exp \left(-\frac{t}{\tau_{1}}\right)+A_{2} \exp \left(-\frac{t}{\tau_{2}}\right)
$$

The time constant is a measure of the lifetime of the transferred electron. Unlike the monoexponential rising transient, a double exponential function is required to fit the decay curve at both $545 \mathrm{~nm}$ and $596 \mathrm{~nm}$. This indicates that the carrier lifetime is different in the dark than in the presence of light, suggesting that photochemical reactions remove electrons. At $545 \mathrm{~nm}$, the time constants are $\tau_{1}=2.5 \mathrm{~s}$ and $\tau_{2}=18.8 \mathrm{~s}$ respectively, whilst they are longer, $\tau_{1}=6.6 \mathrm{~s}$ and $\tau_{2}=25.6 \mathrm{~s}$, for excitation at $596 \mathrm{~nm}$. The two time constants for each wavelength of excitation show that there are at least two independent decay mechanisms. One of these decay times may 
reflect the time taken for transfer from the dopant to the conduction band, which would be longer for the deeper dopant $D 2$, and its subsequent decay time. The second time constant may indicate the timescale of surface reactions at the dopant site. The visible PC decay transient measured at $532 \mathrm{~nm}$ in a nitrogen environment is non-exponential. At short times $(<500 \mathrm{~s})$ only, its decay can be approximated by equation 6 with two distinct timescales, $\tau_{1}=17.7 \mathrm{~s}$ and $\tau_{2}=96.3 \mathrm{~s}$ (calculated over the same temporal range as in Figure 6) both much longer than those obtained with measurement in air, see Figure 7 . This suggests that the removal of electrons from the neutral dopant and/or conduction band in air involves reaction with an atmospheric species, such as oxygen, water or carbon dioxide. The increase in response time when measuring in nitrogen compared to air also happens with $\mathrm{ZnO}$ UV photoconductors. For example, high quality $\mathrm{ZnO}$ nanorods show relatively long UV current recovery times of $2.5 \mathrm{~min}$ in the presence of air and 6 min in pure nitrogen. ${ }^{47}$

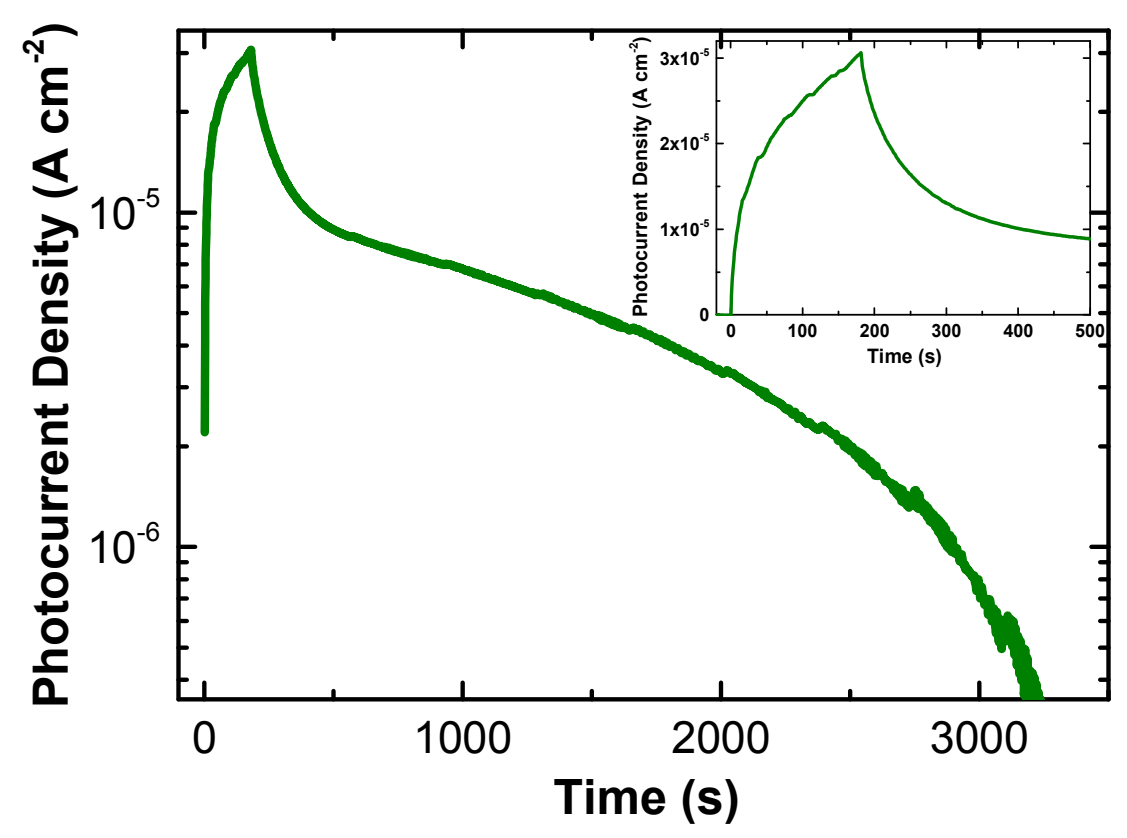


Figure 7. Semi-log plot of photocurrent from air annealed $\mathrm{ZnO}$ photoconductor tested in nitrogen. The sample was excited at a wavelength of $532 \mathrm{~nm}$ for duration of $180 \mathrm{~s}$. The linear plot in the inset is taken over the same temporal range as in Figure 6.

\subsection{Variations of defect/dopant densities with processing conditions}

We found large variations in the magnitude of the PC at $545 \mathrm{~nm}$ depending on device processing, storage conditions and storage environment. Here we attribute these variations to the density of defects/dopants and correlate these measurements to changes in the FTIR spectroscopic transitions of surface species in the $\mathrm{ZnO}$ thin films. 
(a)

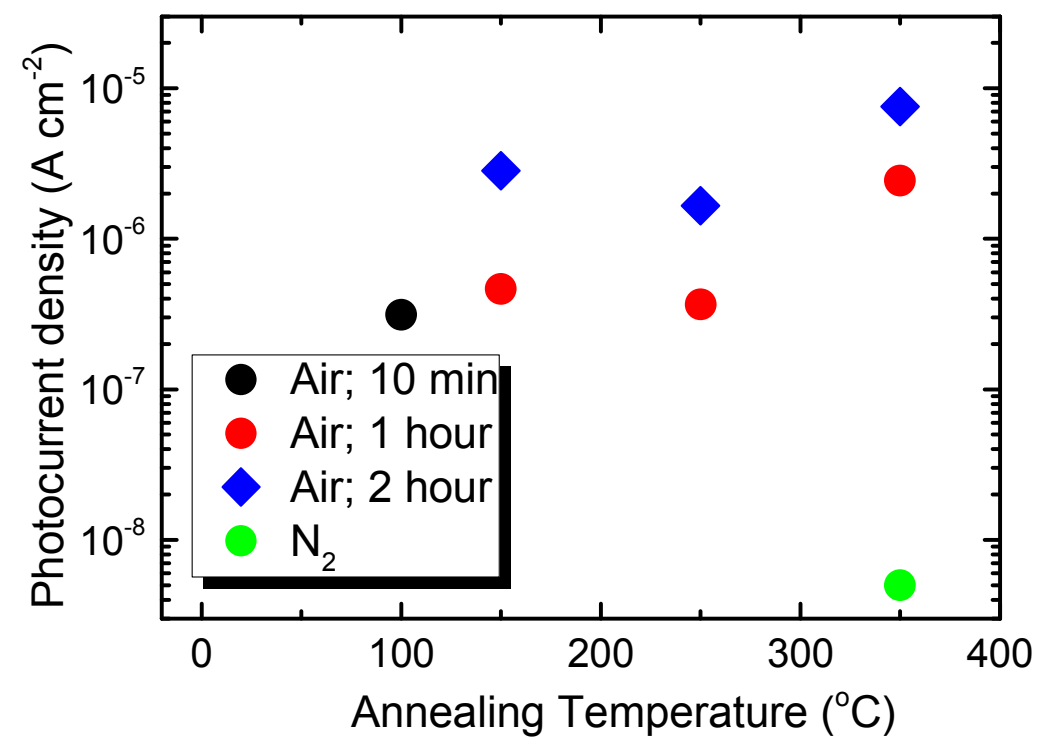

(b)

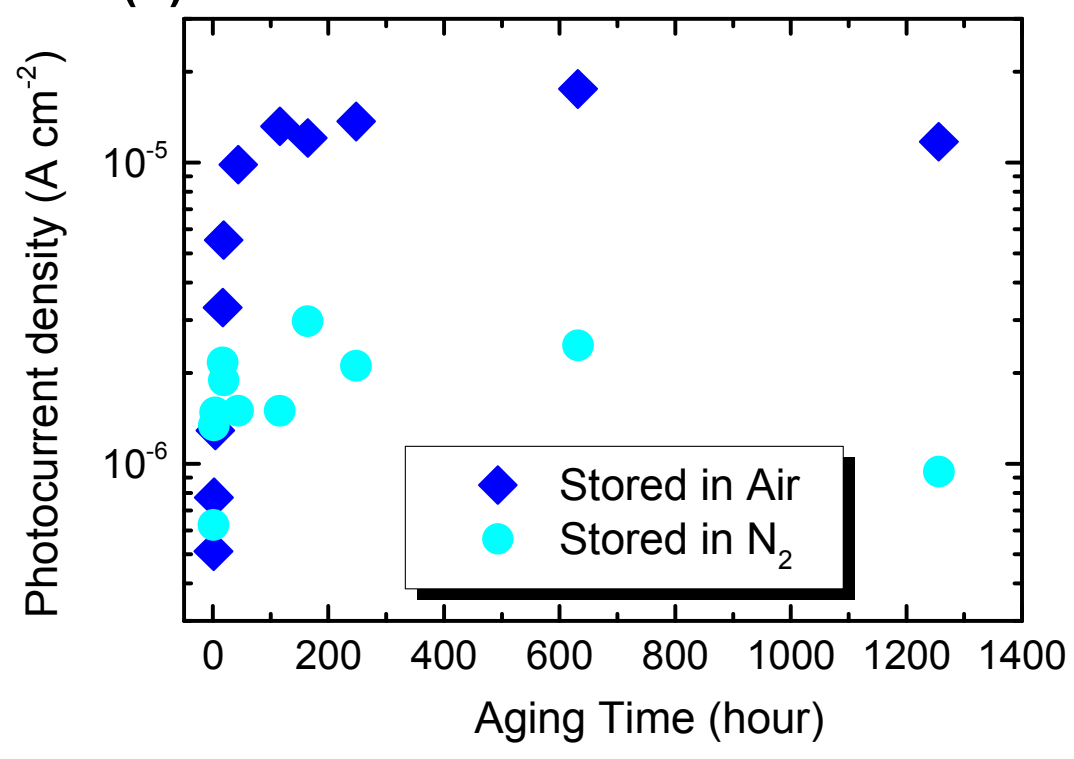

Figure 8. (a) Photocurrent of freshly annealed samples at $550 \mathrm{~nm}$ as a function of annealing temperature. The inset label refers to the annealing atmosphere and annealing time. (b) Variation of photocurrent as a function of storage time in different atmospheres. Both samples were prepared and then annealed in air at $350{ }^{\circ} \mathrm{C}$ for 2 hours. 
Figure 8(a) shows the dependence of the PC peak at $550 \mathrm{~nm}$ on annealing temperature and atmosphere. The highest photocurrent was observed following annealing in air at $350{ }^{\circ} \mathrm{C}$ for 2 hours. However annealing at the same temperature in a nitrogen environment significantly reduces the visible light conductivity. A correlation of these observations with FTIR results given in Figure 3 suggest that there is enhanced PC from samples where the precursor acetate groups are efficiently removed. Possibly the removal of the acetate ligands creates oxygen vacancies thus increasing the density of defect states, $V_{O}^{0}$. Alternatively, or even simultaneously, the oxidising annealing environment may remove traps, which reduce the electron lifetime. Figure 8(b) shows that storage in air after annealing enhances photoconductivity, but very little enhancement is observed on storage in nitrogen. For the former, the signal increases by $\approx 25$ with storage before saturation. There are also significant differences between the FTIR spectroscopic $\mathrm{C}=\mathrm{O}$ and $\mathrm{C}-\mathrm{O}$ signals at $1565 \mathrm{~cm}^{-1}, 1419$ and $1454 \mathrm{~cm}^{-1}$ on storage in air (Figure 3(b)) and nitrogen (Figure 3(c)), both following annealing in air. The intensity of these signals is approximately doubled on storage in air but hardly changes when stored in nitrogen. This is consistent with the capture of $\mathrm{CO}_{2}$ from air, as discussed above. It may be a coincidence that enhanced photoconductivity is associated with carbonate formation. Alternatively it may suggest that shallow donor states local to the vacancies are associated with the adsorbed carbonates. A possible model for this is now discussed. Vacant oxygen interstitial surface sites (VOISSs) exist at the surface of $\mathrm{ZnO}$ NPs in addition to the neutral oxygen vacancy defect, $V_{O}^{0}$. However the former defect is not charged in its neutral state. ${ }^{48}$ It is suggested that photo-excitation can result in electron transfer from $V_{O}^{0}$ to VOISS. ${ }^{48}$ This is a similar reaction to that given in equation 4 with VOISS as $D^{+}$and (VOISS) ${ }^{-}$as $D^{0}$. Furthermore, it is suggested that (VOISS) ${ }^{-}$facilitates 
the adsorption of $\mathrm{CO}_{2}$ in the first step of methanol synthesis, so it may be stabilized here by the capture of free $\mathrm{CO}_{2}$ to form the adsorbed carbonate $\mathrm{CO}_{2}^{-}$. A careful examination of the FTIR spectra before and after long storage in air, see Figure S3, shows the development of transitions from neutral $\mathrm{CO}_{2}$ at $673 \mathrm{~cm}^{-1}, 2332 \mathrm{~cm}^{-1}$ and $2362 \mathrm{~cm}^{-1}$ after storage. ${ }^{49,50} \mathrm{We}$ do not believe that water and oxygen in the atmospheric air are responsible for the narrow- band $\mathrm{PC}$ of $\mathrm{ZnO}$ NPs in the green. Water, for instance, is found to increase the electrical conductivity of $\mathrm{ZnO}$ by the protonic conduction. ${ }^{51}$ On the other hand, it is well known that oxygen is associated with PC of $\mathrm{ZnO}$ NPs in the UV, particularly when the surface to volume ratio is high ${ }^{52,53}$. We show in a forthcoming publication that PC in the UV also changes in its intensity with storing, but the changes do not correlate with those of the green signal, shown in Figure 8(b). Hence narrowband $\mathrm{PC}$ in the green is not associated with oxygen.

\subsection{Pixelated dual wavelength detector}

We now present a low-cost and scalable approach to the fabrication of pixelated $\mathrm{ZnO}$ thin film, with different pixels showing different spectral responses. A two pixel device is produced where one pixel shows both a UV and green photoresponse, whilst the green response is suppressed in the second pixel. A photolithographic process using the positive photoresist AZ5214 (Microchemicals Gmbh) is used to define the pixels. $\mathrm{ZnO}$ is insoluble in the solvent, acetone, which dissolves the photoresist. The photoresist developer dissolves both the exposed photoresist and $\mathrm{ZnO}$. Figure 9 illustrates the key device processing steps. A solution-processed thin film of $\mathrm{ZnO}$ on pre-patterned ITO coated electrode is processed photolithographically to define a single pixel $\mathrm{P} 1$. This is annealed in air at $350^{\circ} \mathrm{C}$ to optimise the efficiency of $\mathrm{PC}$ in the green spectral region. A similar photolithography step is used to mask P1with an overlying photoresist layer 
before spin-casting a second thin film of $\mathrm{ZnO}$ over the complete substrate. The second pixel is photolithographically patterned and developed. The substrate is finally washed with acetone to remove the photoresist overlying $\mathrm{P} 1$ and $\mathrm{P} 2$. A full description of all the fabrication steps is given in the supporting information.

Substrate

$\mathrm{ZnO}$ nanoparticles

Photoresist

Mask

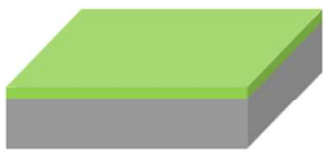

Photolithography
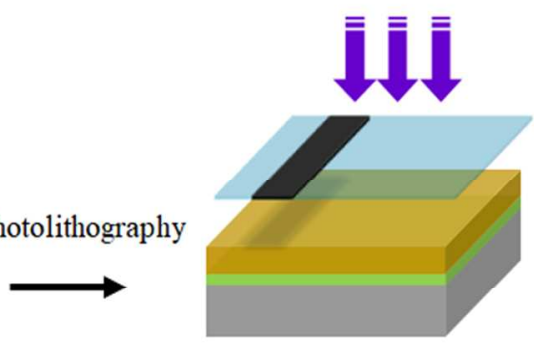

Developer removes $\mathrm{ZnO}$,

Acetone removes photoresist,

Baked at $350^{\circ} \mathrm{C}$.
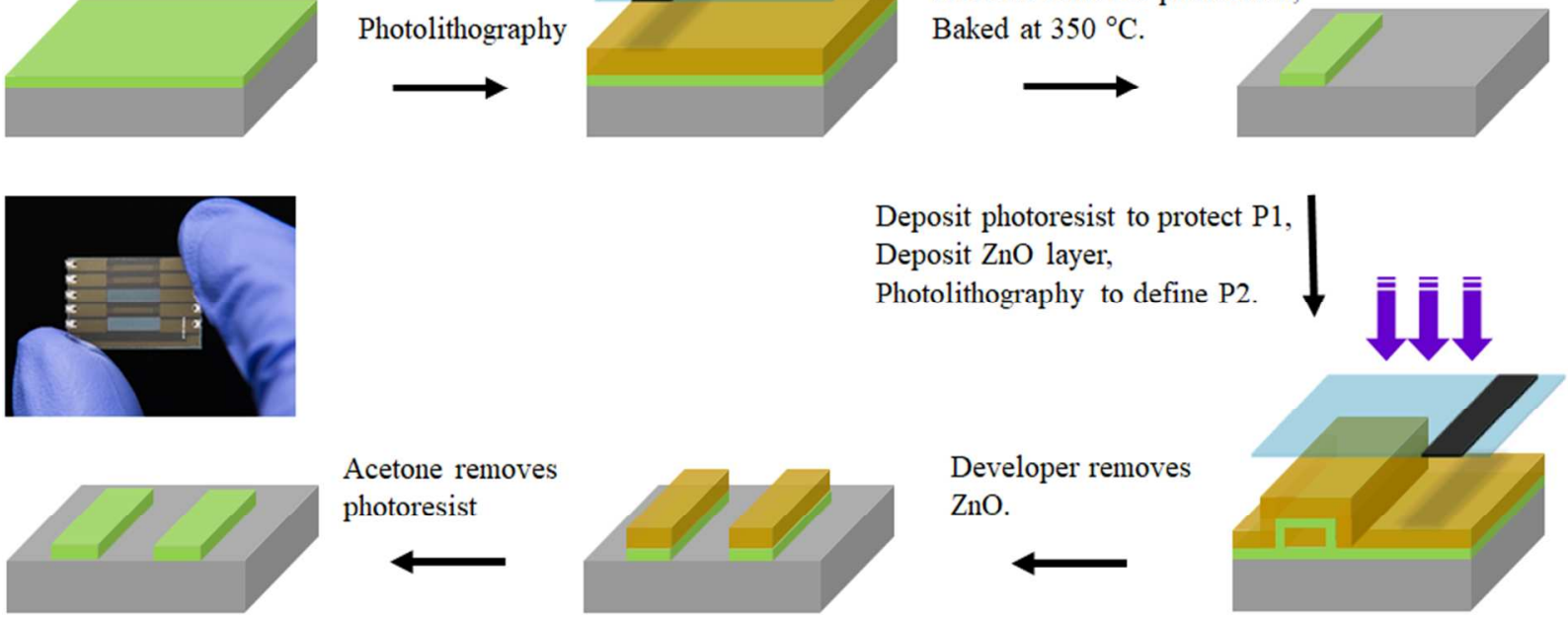

Figure 9. Key steps in processing a two pixel device, where the left-hand pixel 1, P1, is optimised for green light photodetection. An image of the two pixel device is also shown. 
(a)

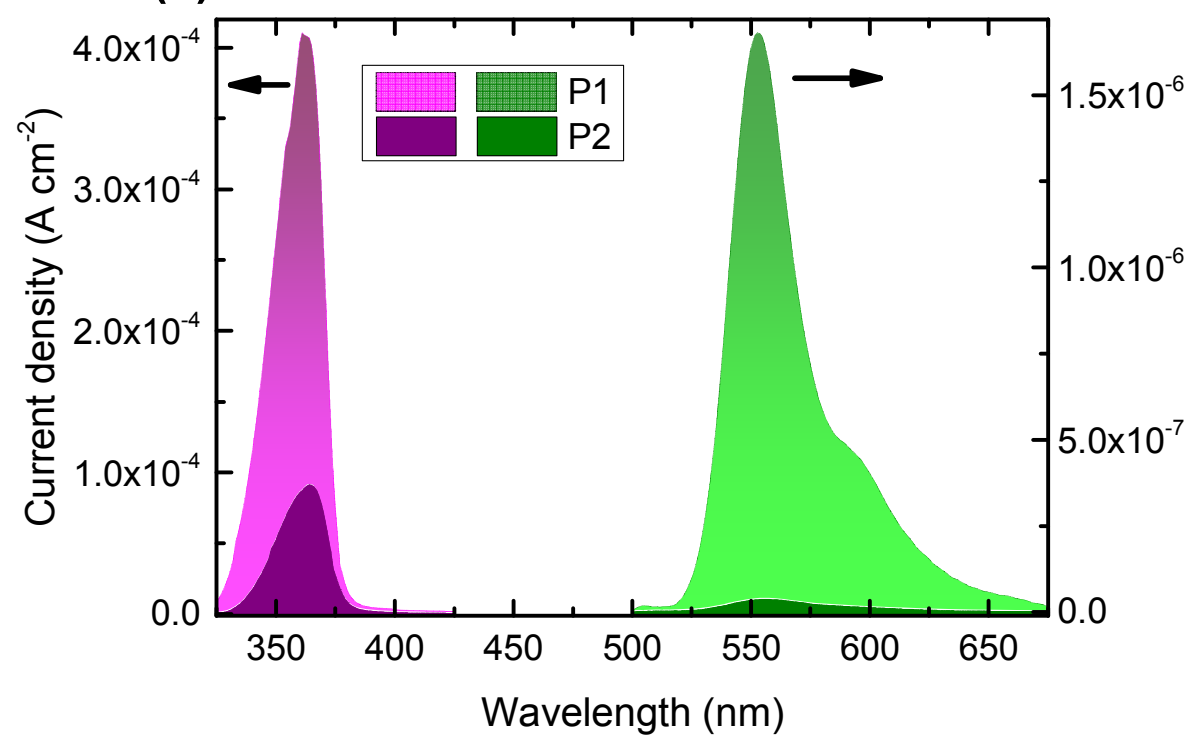

(b)

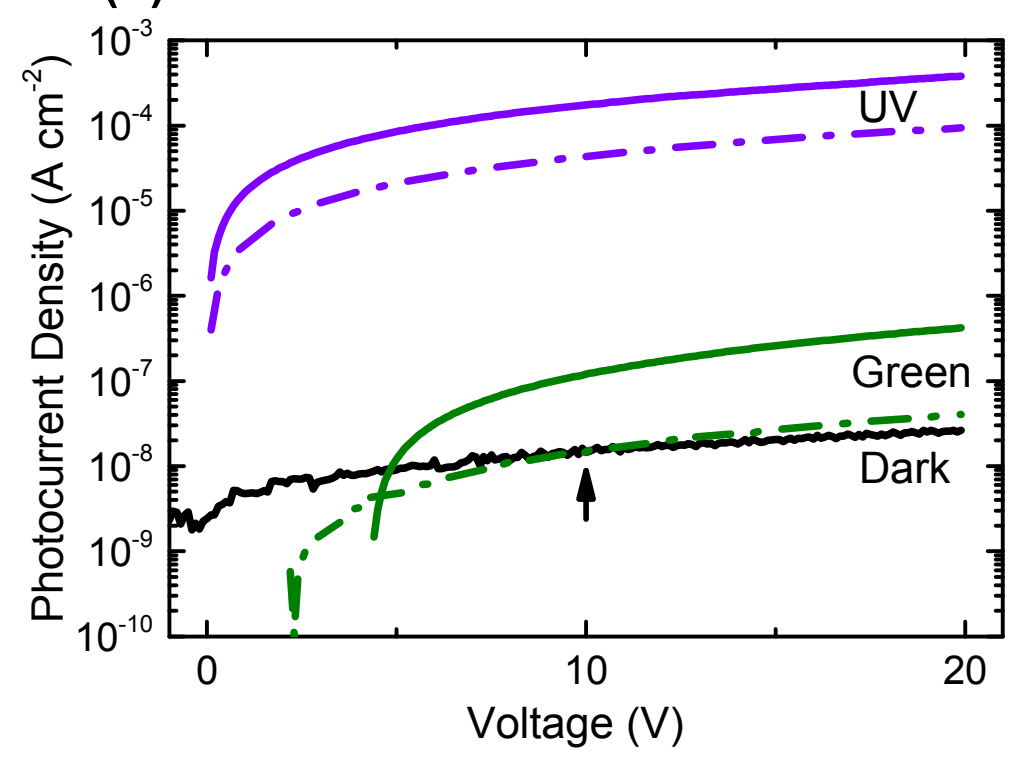

Figure 10. Photocurrent from two pixels on the same substrate. The pale and darkly shaded areas show data from pixels P1 and P2 respectively. (a) Photocurrent spectrum showing UV and green signals. (b) Photocurrent versus voltage for both pixels. The arrow indicates the voltage at which the green signal equals the dark current in P2. Note the dark current is smaller than that shown in Figure 4(b), because of differences in the processing conditions. 
Figure 10 (a) shows the spectrum from both pixels excited under the same conditions. P1 has the greater current density in the UV and green. The UV current density is decreased by a factor of 4.5 in $\mathrm{P} 2$ compared to $\mathrm{P} 1$, whilst the green $\mathrm{PC}$ in $\mathrm{P} 2$ is a factor of 44 less than that of $\mathrm{P} 1$. Figure 10 (b) shows that the photocurrent can drop below the dark current. This may result from photocatalytic reactions which remove groups, such as adsorbed $-\mathrm{OH}$, which contribute to the dark current, so that the dark current is lowered for some time after photoexcitation. Figure 10 (b) also shows that the voltage to the device can be adjusted, here to below about $10 \mathrm{~V}$ as indicated by the arrow in the figure, so that the green photocurrent drops to a value below the dark current. Under these circumstances, P1 can act as a dual wavelength photoconductor whilst P2 only detects the UV light. Note that the current density in the UV is over two orders of magnitude greater than that of the green. They can be equalised by coating the device with a UV absorbing thin film.

\section{Conclusion}

Normally sub-band gap PC extends over a broad spectral range and is attributed to optical transitions between defect states and the conduction or valence band. Here we introduce a model involving electron transfer between deep defect states and discrete shallow donors to account for the unusually spectrally sharp PC observed in the green spectral region of ZnO nanocrystalline photoconductors. The PC is enhanced by annealing and storing the photoconductor in air and the enhancement is correlated to the surface capture of carbon dioxide. We exploit this control of PC to make low-cost dual wavelength photodetectors. The green PC response can be spatially patterned by multi-step photolithography so that dual (ultraviolet and green) and single (ultraviolet only) wavelength detecting pixels can be produced on the same substrate. Hence, a 
2D detector array can be fabricated with a spatial response which varies with wavelength. This is interesting for security and imaging applications. A similar approach could be used for full colour imaging, where gold or aluminium NP-doped $\mathrm{ZnO}$ pixels could be used to obtain blue and red PC via plasmonic effects. ${ }^{54,55}$

\section{Acknowledgements}

The Authors gratefully acknowledge the Iraqi Ministry of Higher Education and Scientific Research for partly funding this work. The EPSRC is also thanked for partial funding under grant $\mathrm{EP} / \mathrm{J} 001597 / 1$.

\section{Supporting information}

XRD of ZnO NPs, Current transient in the visible and UV, FTIR spectra of ZnO sample after storing in air for 15 days and full photolithography steps followed to pixelate the photodetector device. 


\section{References}

(1) Thomas, S. R.; Pattanasattayavong, P.; Anthopoulos, T. D. Solution-Processable Metal Oxide Semiconductors for Thin-Film Transistor Applications. Chem. Soc. Rev. 2013, 42, 6910.

(2) Choy, W. C. H.; Zhang, D. Solution-Processed Metal Oxides as Efficient Carrier Transport Layers for Organic Photovoltaics. Small 2016, 12, 416-431.

(3) Sessolo, M.; Bolink, H. J. Hybrid Organic-Inorganic Light-Emitting Diodes. Adv. Mater. 2011, 23, 1829-1845.

(4) Beek, W. J. E.; Wienk, M. M.; Janssen, R. A. J. Efficient Hybrid Solar Cells from Zinc Oxide Nanoparticles and a Conjugated Polymer. Adv. Mater. 2004, 16, 1009-1013.

(5) Guo, F.; Yang, B.; Yuan, Y.; Xiao, Z.; Dong, Q.; Bi, Y.; Huang, J. A Nanocomposite Ultraviolet Photodetector Based on Interfacial Trap-Controlled Charge Injection. Nat. Nanotechnol. 2012, 7, 798-802.

(6) Basak, D.; Amin, G.; Mallik, B.; Paul, G. K.; Sen, S. K. Photoconductive UV Detectors on Sol-gel-Synthesized ZnO Films. J. Cryst. Growth 2003, 256, 73-77.

(7) Giannakoudakis, D. A.; Arcibar-Orozco, J. A.; Bandosz, T. J. Key Role of Terminal Hydroxyl Groups and Visible Light in the Reactive Adsorption/catalytic Conversion of Mustard Gas Surrogate on Zinc (Hydr)oxides. Appl. Catal. B Environ. 2015, 174-175, 96-104.

(8) Manekkathodi, A.; Lu, M.-Y.; Wang, C. W.; Chen, L.-J. Direct Growth of Aligned Zinc Oxide Nanorods on Paper Substrates for Low-Cost Flexible Electronics. Adv. Mater. 
2010, 22, 4059-4063.

(9) Weintraub, B.; Zhou, Z.; Li, Y.; Deng, Y. Solution Synthesis of One-Dimensional ZnO Nanomaterials and Their Applications. Nanoscale 2010, 2, 1573.

(10) Sarkar, S.; Basak, D. Self Powered Highly Enhanced Dual Wavelength ZnO@CdS CoreShell Nanorod Arrays Photodetector: An Intelligent Pair. ACS Appl. Mater. Interfaces 2015, 7, 16322-16329.

(11) Tak, Y.; Yong, K. Controlled Growth of Well-Aligned ZnO Nanorod Array Using a Novel Solution Method. J. Phys. Chem. B 2005, 109, 19263-19269.

(12) Laurenti, M.; Verna, A.; Fontana, M.; Quaglio, M.; Porro, S. Selective Growth of ZnO Nanowires on Substrates Patterned by Photolithography and Inkjet Printing. Appl. Phys. A 2014, 117, 901-907.

(13) Shi, R.; Huang, C.; Zhang, L.; Amini, A.; Liu, K.; Shi, Y.; Bao, S.; Wang, N.; Cheng, C. Three Dimensional Sculpturing of Vertical Nanowire Arrays by Conventional Photolithography. Sci. Rep. 2016, 6, 18886.

(14) Gwinner, M. C.; Vaynzof, Y.; Banger, K. K.; Ho, P. K. H.; Friend, R. H.; Sirringhaus, H. Solution-Processed Zinc Oxide as High-Performance Air-Stable Electron Injector in Organic Ambipolar Light-Emitting Field-Effect Transistors. Adv. Funct. Mater. 2010, 20, $3457-3465$.

(15) Liang, S.; Sheng, H.; Liu, Y.; Huo, Z.; Lu, Y.; Shen, H. ZnO Schottky Ultraviolet Photodetectors. J. Cryst. Growth 2001, 225, 110-113.

(16) Soci, C.; Zhang, A.; Xiang, B.; Dayeh, S. A.; Aplin, D. P. R.; Park, J.; Bao, X. Y.; Lo, Y. 
H.; Wang, D. ZnO Nanowire UV Photodetectors with High Internal Gain. Nano Lett. 2007, 7, 1003-1009.

(17) Ahn, S. E.; Lee, J. S.; Kim, H.; Kim, S.; Kang, B. H.; Kim, K. H.; Kim, G. T. Photoresponse of Sol-Gel-Synthesized ZnO Nanorods. Appl. Phys. Lett. 2004, 84, 50225024.

(18) Jin, Y.; Wang, J.; Sun, B.; Blakesley, J. C.; Greenham, N. C. Solution-Processed Ultraviolet Photodetectors Based on Colloidal ZnO Nanoparticles. Nano Lett. 2008, 8, $1649-1653$.

(19) Choi, S.; Phillips, M. R.; Aharonovich, I.; Pornsuwan, S.; Cowie, B. C. C.; Ton-That, C. Photophysics of Point Defects in ZnO Nanoparticles. Adv. Opt. Mater. 2015, 3, 821-827.

(20) Sun, B.; Sirringhaus, H. Solution-Processed Zinc Oxide Field-Effect Transistors Based on Self-Assembly of Colloidal Nanorods. Nano Lett. 2005, 5, 2408-2413.

(21) Pacholski, C; Kornowski, A.; Weller, H. Self-Assembly of ZnO: From Nanodots to Nanorods. Angew. Chemie Int. Ed. 2002, 41, 1188-1191.

(22) Luo, M.; Shen, C.; Feltis, B. N.; Martin, L. L.; Hughes, A. E.; Wright, P. F. A.; Turney, T. W. Reducing ZnO Nanoparticle Cytotoxicity by Surface Modification. Nanoscale 2014, 6, 5791.

(23) Lupan, O.; Chow, L.; Ono, L. K.; Cuenya, B. R.; Chai, G.; Khallaf, H.; Park, S.; Schulte, A. Synthesis and Characterization of Ag- or Sb-Doped $\mathrm{ZnO}$ Nanorods by a Facile Hydrothermal Route. J. Phys. Chem. C 2010, 114, 12401-12408.

(24) Zhang, X.; Qin, J.; Xue, Y.; Yu, P.; Zhang, B.; Wang, L.; Liu, R. Effect of Aspect Ratio 
and Surface Defects on the Photocatalytic Activity of ZnO Nanorods. Sci. Rep. 2015, 4, 4596.

(25) Sun, R.-D.; Nakajima, A.; Fujishima, A.; Watanabe, T.; Hashimoto, K. Photoinduced Surface Wettability Conversion of $\mathrm{ZnO}$ and TiO 2 Thin Films. J. Phys. Chem. B 2001, $105,1984-1990$.

(26) A.V. Naumkin, A. Kraut-Vass, S. W. Gaarenstroom, C. J. P. NIST X-ray Photoelectron Spectroscopy Database Version 4.1.

(27) Lin, C.-C.; Li, Y.-Y. Synthesis of ZnO Nanowires by Thermal Decomposition of Zinc Acetate Dihydrate. Mater. Chem. Phys. 2009, 113, 334-337.

(28) Sakohara, S.; Ishida, M.; Anderson, M. a. Visible Luminescence and Surface Properties of Nanosized ZnO Colloids Prepared by Hydrolyzing Zinc Acetate. J. Phys. Chem. B 1998, $102,10169-10175$.

(29) Kumar, S.; Sahare, P. D. Effects of Annealing on the Surface Defects of Zinc Oxide Nanoparticles. World Sci. 2012, 7, 1-9.

(30) Gankanda, A.; Cwiertny, D. M.; Grassian, V. H. Role of Atmospheric CO2 and H2O Adsorption on $\mathrm{ZnO}$ and $\mathrm{CuO}$ Nanoparticle Aging: Formation of New Surface Phases and the Impact on Nanoparticle Dissolution. J. Phys. Chem. C 2016, 120, 19195-19203.

(31) Chen, K. J.; Hung, F. Y.; Chang, S. J.; Young, S. J. Optoelectronic Characteristics of UV Photodetector Based on ZnO Nanowire Thin Films. J. Alloys Compd. 2009, 479, 674-677.

(32) Hsu, C. L.; Lin, Y. H.; Wang, L. K.; Hsueh, T. J.; Chang, S. P.; Chang, S. J. Tunable UVand Visible-Light Photoresponse Based on P-ZnO Nanostructures/n-ZnO/Glass Peppered 
with Au Nanoparticles. ACS Appl. Mater. Interfaces 2017, 9, 14935-14944.

(33) Fan, Z.; Chang, P.; Lu, J. G.; Walter, E. C.; Penner, R. M.; Lin, C.; Lee, H. P. Photoluminescence and Polarized Photodetection of Single ZnO Nanowires. Appl. Phys. Lett. 2004, 85, 6128-6130.

(34) Bera, A.; Basak, D. Role of Defects in the Anomalous Photoconductivity in $\mathrm{ZnO}$ Nanowires. Appl. Phys. Lett. 2009, 94, 2007-2010.

(35) Sett, D.; Sarkar, S.; Basak, D. A Successive Photocurrent Transient Study to Probe the Sub-Band Gap Electron and Hole Traps in ZnO Nanorods. RSC Adv. 2014, 4, 5855358558.

(36) Moazzami, K.; Murphy, T. E.; Phillips, J. D.; Cheung, M. C.-K.; Cartwright, a N. SubBandgap Photoconductivity in ZnO Epilayers and Extraction of Trap Density Spectra. Semicond. Sci. Technol. 2006, 21, 717-723.

(37) Kavitha, M. K.; Jinesh, K. B.; Philip, R.; Gopinath, P.; John, H. Defect Engineering in ZnO Nanocones for Visible Photoconductivity and Nonlinear Absorption. Phys. Chem. Chem. Phys. 2014, 16, 25093-25100.

(38) Park, C.; Lee, J.; Chang, W. S. Geometrical Separation of Defect States in ZnO Nanorods and Their Morphology-Dependent Correlation between Photoluminescence and Photoconductivity. J. Phys. Chem. C 2015, 119, 16984-16990.

(39) Lany, S.; Zunger, A. Anion Vacancies as a Source of Persistent Photoconductivity in II-VI and Chalcopyrite Semiconductors. Phys. Rev. B 2005, 72, 35215.

(40) Janotti, A.; Van De Walle, C. G. Native Point Defects in ZnO. Phys. Rev. B - Condens. 
Matter Mater. Phys. 2007, 76, 1-22.

(41) Vanheusden, K.; Warren, W. L.; Seager, C. H.; Tallant, D. R.; Voigt, J. A.; Gnade, B. E. Mechanisms behind Green Photoluminescence in ZnO Phosphor Powders. J. Appl. Phys. 1996, 79, 7983-7990.

(42) Wang, X. J.; Vlasenko, L. S.; Pearton, S. J.; Chen, W. M.; Buyanova, I. a. Oxygen and Zinc Vacancies in as-Grown ZnO Single Crystals. J. Phys. D. Appl. Phys. 2009, 42, 175411.

(43) Janotti, A.; Van De Walle, C. G. Oxygen Vacancies in ZnO. Appl. Phys. Lett. 2005, 87, 13.

(44) Hofmann, D. M.; Hofstaetter, A.; Leiter, F.; Zhou, H.; Henecker, F.; Meyer, B. K.; Orlinskii, S. B.; Schmidt, J.; Baranov, P. G. Hydrogen: A Relevant Shallow Donor in Zinc Oxide. Phys. Rev. Lett. 2002, 88, 45504.

(45) Eppler, A. M.; Ballard, I. M.; Nelson, J. Charge Transport in Porous Nanocrystalline Titanium Dioxide. Phys. E Low-dimensional Syst. Nanostructures 2002, 14, 197-202.

(46) Reemts, J.; Kittel, A. Persistent Photoconductivity in Highly Porous ZnO Films. J. Appl. Phys. 2007, 101, 13709.

(47) Witkowski, B. S.; Wachnicki, L.; Gieraltowska, S.; Sybilski, P.; Kopalko, K.; Stachowicz, M.; Godlewski, M. UV Detector Based on Zinc Oxide Nanorods Obtained by the Hydrothermal Method. Phys. Status Solidi 2014, 11, 1447-1451.

(48) French, S. A.; Sokol, A. A.; Bromley, S. T.; Catlow, C. R. A.; Sherwood, P. Identification and Characterization of Active Sites and Their Catalytic Processes - the $\mathrm{Cu} / \mathrm{ZnO}$ 
Methanol Catalyst. Top. Catal. 2003, 24, 161-172.

(49) Saussey, J.; Lavalley, J.-C.; Bovet, C. Infrared Study of CO2 Adsorption on ZnO. Adsorption Sites. J. Chem. Soc. Faraday Trans. 1 Phys. Chem. Condens. Phases 1982, 78, 1457.

(50) Hlaing Oo, W. M.; McCluskey, M. D.; Lalonde, A. D.; Norton, M. G. Infrared Spectroscopy of ZnO Nanoparticles Containing $\mathrm{CO}$ [sub 2] Impurities. Appl. Phys. Lett. 2005, $86,73111$.

(51) Chen, Z.; Lu, C. Humidity Sensors: A Review of Materials and Mechanisms. Sens. Lett. 2005, 3, 274-295.

(52) Nasiri, N.; Bo, R.; Wang, F.; Fu, L.; Tricoli, A. Ultraporous Electron-Depleted ZnO Nanoparticle Networks for Highly Sensitive Portable Visible-Blind UV Photodetectors. Adv. Mater. 2015, 27, 4336-4343.

(53) McCluskey, M. D.; Jokela, S. J. Defects in ZnO. J. Appl. Phys. 2009, 106, 0-13.

(54) Mubeen, S.; Hernandez-Sosa, G.; Moses, D.; Lee, J.; Moskovits, M. Plasmonic Photosensitization of a Wide Band Gap Semiconductor: Converting Plasmons to Charge Carriers. Nano Lett. 2011, 11, 5548-5552.

(55) Zheng, B. Y.; Wang, Y.; Nordlander, P.; Halas, N. J. Color-Selective and CMOSCompatible Photodetection Based on Aluminum Plasmonics. Adv. Mater. 2014, 26, 63186323. 


\section{Table of Contents graphic}
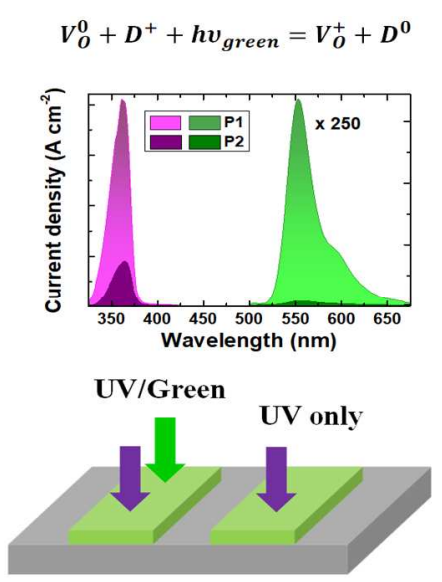

ACS Paragon Plus Environment 